\title{
HAVE TRACTOR MANUFACTURERS BORE IN MIND SOIL COMPACTION OVER THE LAST 40 YEARS?
}

\begin{abstract}
Antonio COMPARETTI, Department of Agricultural, Food and Forest Sciences (SAAF), University of Palermo, Piazza Marina, 61, 90133 Palermo PA, Italy, antonio.comparetti@unipa.it

Pierluigi FEBO, Department of Agricultural, Food and Forest Sciences (SAAF), University of Palermo, Piazza Marina, 61, 90133 Palermo PA, Italy, pierluigi.febo@unipa.it

Carlo GRECO, Council for Agricultural Research and Economics (CREA), Research Centre Protection and Certification, S.S. 113 - Km 245.500, 90011 Bagheria, Italy, carlo.greco@unipa.it (corresponding author)

Santo ORLANDO, Department of Agricultural, Food and Forest Sciences (SAAF), University of Palermo, Piazza Marina, 61, 90133 Palermo PA, Italy, santo.orlando@unipa.it

Soil compaction is the compression of soil particles in a lower volume as a consequence of the reduction of the spaces existing among the particles themselves. This phenomenon is caused by natural forces and, above all, human ones. In order to estimate the field damages that can be caused by the traffic of agricultural machines, the load and the mean pressure applied by the tyres onto the soil can be measured. The research aim is to determine the pressure applied by each considered tractor onto the soil, in order to evaluate the effect of the traffic of tractors onto the soil itself.

A total of 783 wheeled tractors manufactured and marketed in the last 35 years (1979-2014) was investigated. Data like construction year, manufacturer, model, power, total weight, weight (load) on the front and rear axle, wheelbase, front and rear type of tyres, as well as the tyre specifications, were collected.

The mean pressure applied by each tractor onto the soil was computed by dividing the load applied on each tyre by its contact area. In order to reduce the pressure applied by agricultural machines onto the soil, the vehicle mass and, therefore, weight, has to be reduced, or the tyre contact area on the soil has to be increased. Farmers can easily increase the tyre contact area, by decreasing the tyre inflation pressure or increasing the tyre width, i.e. mounting tyres having a larger section width, or Terra Tyres, or twin-tyres.

Over the last 40 years: the mean power of mechanical four wheel drive (MFWD) tractors and four wheel drive (4WD) (isodiametric tyres) tractors increased, while that of two wheel drive (2WD) tractors remained constant; the power and the total weight increased, while the weight-power ratio decreased. Practically the reduction of the mean pressure on the soil resulted rather limited, meaning that tractor manufacturers have not bore in mind soil compaction.
\end{abstract}

Keywords: contact area, ground pressure, soil compaction, soil protection, tractor tyres.

\section{INTRODUCTION}

Soil compaction is one of the eight factors causing soil degradation identified by the EU in the "Strategy for soil protection" (EU Commission 2006/231). Soil compaction is the decay of the soil structure caused by the pressure applied on it, so that porosity and permeability decrease, while bulk density and cone penetrometer resistance increase (Carrara et al., 2003, 2005, 2007; Comparetti et al., 2013). Over the last 40 years soil compaction was caused by the traffic of agricultural machines having very higher and higher power and weight. This phenomenon occurred together with the reduction of soil organic matter and, therefore, fertility and crop yield (by 20\% ca.) (Pagliai, 2003).

Soil compaction is the compression of soil particles in a lower volume as consequence of the reduction of the spaces existing among the particles themselves. This phenomenon can be caused by natural forces (rain, clay swelling and shrinkage, deep penetration of plant roots into the soil, etc.) but especially by human activities (animal trampling or mainly pressure exerted by agricultural machines through their tyres or tracks, or also the compression exerted by agricultural machines working parts and/or tools).

Compaction affect soil structure, not only in the shallowest layers but also in the deepest ones, e.g. causing a soil pan at the machine working depth (Vignozzi, 2000). This layer has a low permeability to water, nutrients and plant roots (Febo, 1991).

When compacted, a soil has lower porosity $(1 / 3-1 / 4)$ and, therefore, less air, so that $\mathrm{NO}_{3}$ is converted into $\mathrm{N}_{2}$, that goes in the atmosphere, while heavy metals go in the soil water (Benedetti e De Bertoldi, 2000). As a consequence, the activity of

Copyright () 2019 The Authors. Published by Vytautas Magnus University. This is an open-access article distributed under the terms of the Creative Commons Attribution License (CC BY 4.0), which permits unrestricted use, distribution, and reproduction in any medium, provided the original author and source are credited. 
bacteria becomes slow, together with the breakdown of organic matter and the release of nutrients (Pagliai, 2003). The diameter, length and morphology of plant roots are negatively affected by soil compaction (Atwell, 1990), whereas, an optimal soil structure promotes seed germination and the adsorption of water and nutrients by the roots, so that crop yield increases. Soil compaction affects not only the soil where roots grow but also the subsoil, where water and fertilisation nutrients may not arrive. Not considering soil texture, a dry soil is more resistant to compaction rather than a moist or wet one (Febo et al., 1999).

In order to reduce soil compaction caused by the traffic of agricultural machines, type of tyres and their inflation pressure should be accurately selected. Furthermore, tillage methods different from ploughing should be implemented, in order to prevent the formation of a soil pan.

The problem of soil compaction, causing the decay of soil structure and its capability to be tilled, as well as influencing plant growth and crop yield, aroused with the advent of agricultural mechanisation and with the almost constant increase of the power and the weight of the machines (Febo and Pessina, 1987; Pessina et al., 2002). In order to estimate the field damages that can be caused by the traffic of agricultural machines, the pressure applied by the tyres or tracks onto the soil can be measured (Vermeulen and Perdok, 1994).

Not considering track-laying tractors, in the case of wheeled tractors both the tyres and soil are sensitive to deformation. Therefore, the mean ground pressure can be quickly and accurately estimated for several combinations of tractor weight/tyres, in order to evaluate the possibility of soil compaction (Comparetti et al., 2010).

This research aims to assess whether the manufacturers, in the last 40 years, have produced tractors by paying attention to minimise soil compaction.

\section{METHODS}

A total of 783 wheeled tractors manufactured and marketed in the last 35 years (1979-2014) was investigated using the data published in the Italian homologation certificates and in the OECD test reports. Data like construction year, manufacturer, model, power, total weight, weight (load) on the front and rear axle, wheelbase, front and rear type of tyres, as well as the tyre specifications, were collected.

Figure 1 shows the features of the examined sample of 783 wheeled tractors, distinguished in two wheel drive (2WD) tractors, mechanical four wheel drive (MFWD) tractors and four wheel drive (4WD) (isodiametric tyres) tractors (on the left), as well as in the power classes defined in the EC Directives 2000/25/EC and 2005/13/EC (on the right).

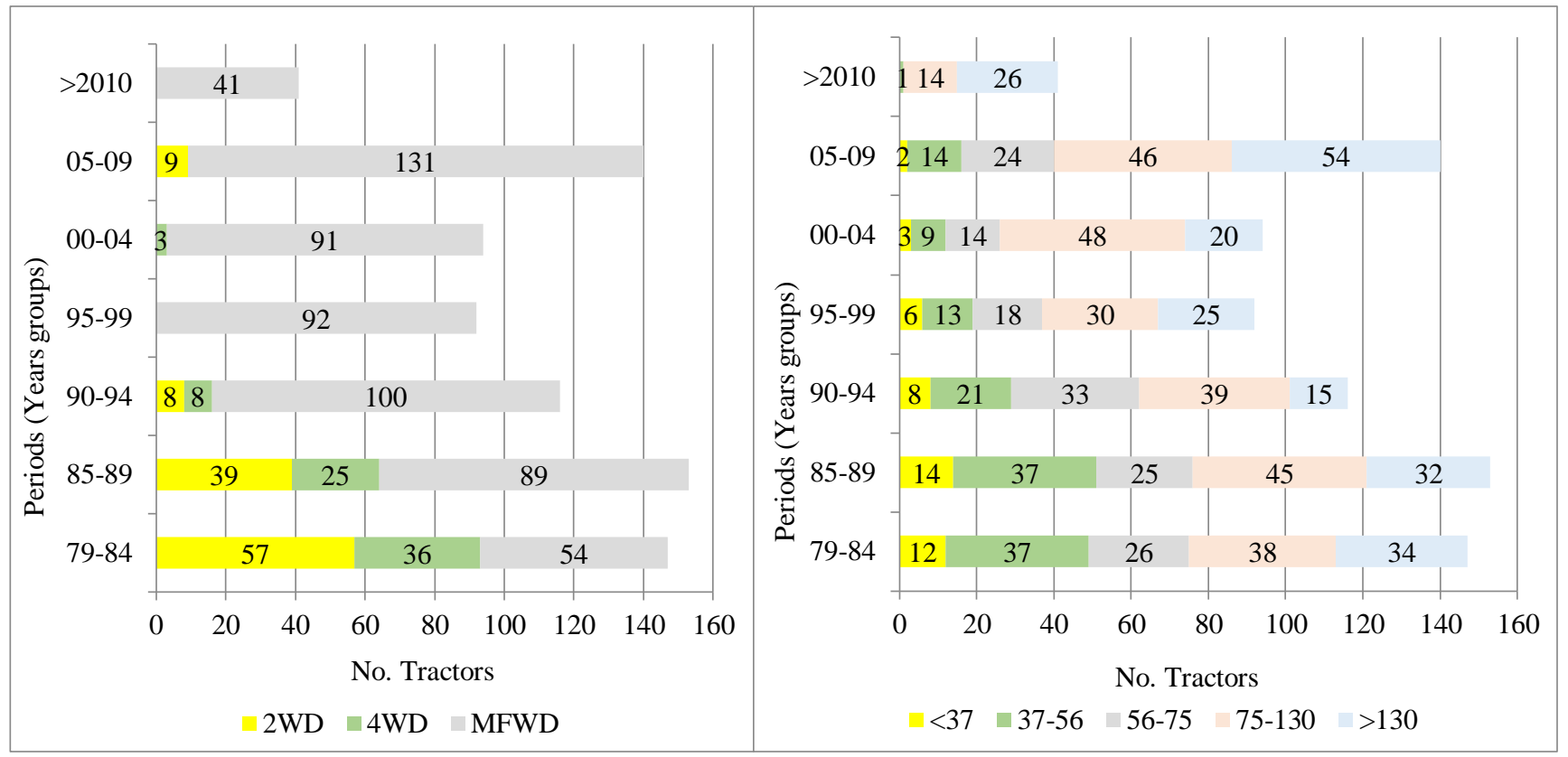

Figure 1. Left: Number of tractors in different periods, distinguished in 2WD, 4WD and MFWD. Right: Number of tractors in different periods, distinguished in power classes (kW), that are defined according the EC Directives 2000/25/EC and 2005/13/EC.

By using the load applied on the front and rear axle, the mean pressure $\left(M_{p}\right)$ applied by each tractor with its fitted tyres on the ground was computed dividing the load on the wheel $\left(G_{t}\right)$ by the contact area of each mounted tyre (A) (Tijink, 1994).

$$
M_{p}=\frac{G_{t}}{A}(1)
$$


The first parameter $G_{t}$ can be easily determined from the tractor data, i.e. dividing by 2 the load on each axle.

The second parameter $(A)$ is not immediately determined but it is possible to estimate it using several empirical methods and prediction models.

Young et al. (1980), Plackett (1984), Dexter et al. (1988), Komandi (1976, 1990), Schwanghart (1994) and Hallonborg (1996) investigated the problems of ground pressure and contact area and, in some cases, proposed to measure the tyre contact area on a hard surface using a press and varying the load applied on the tyre, as well as elaborated several prediction models.

Febo et al. (1999) have examined and verified, with practical tests, the usefulness of some of these prediction models and concluded that the model proposed by Hallonborg, based on super ellipse theory, is the one that provides results closer to the reality, both in terms of small differences between the computed contact area values and the measured ones, as well as of similarity between the predicted contact area shape and that actually measured.

In this research, in order to compute the tyre contact area, the prediction model proposed by Hallonborg, taking into account the width $\left(w_{c}\right)$ and length $\left(l_{c}\right)$ of the contact area (Fig. 2), was firstly used.

The contact length can be computed by using the formula 2 :

$$
l_{c}=2 \cdot \sqrt{r_{n}^{2}-r_{i}^{2}}
$$

where: $l_{c}=$ computed length of the contact $(\mathrm{mm}) ; r_{n}=$ nominal radius $=1 / 2$ external diameter; $r_{i}=$ index radius $=$ loaded radius.
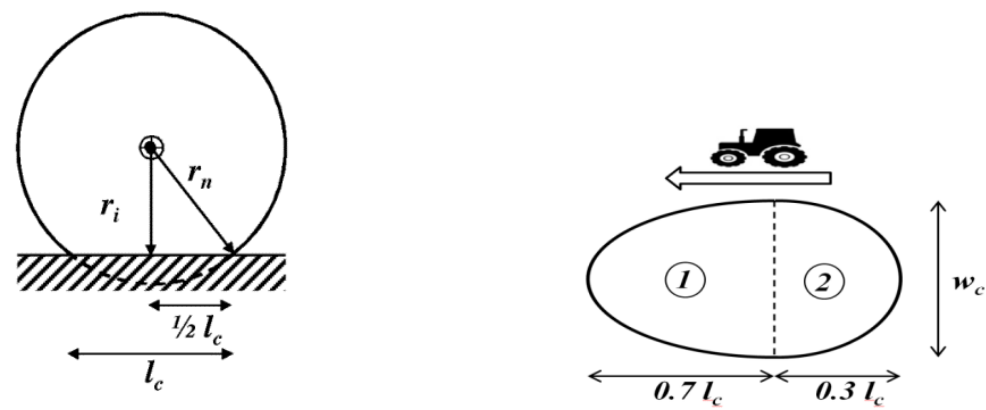

Figure 2. Geometrical length of the contact area. Width and length of two halves (1: front; 2: rear) that constitute the contact area, according to Hallonborg model.

The contact area, according to the above model, is computed through the formula 3, using the shape coefficients of 0.813 and 0.909 for the front and rear parts of the tyre footprint, respectively. These coefficients were experimentally obtained through practical measurements for different tyres by various authors (Febo et al. 1990, Grečenko 1995):

$$
A=\left(0.7 \cdot l_{c} \cdot w_{c} \cdot 0.813\right)+\left(0.3 \cdot l_{c} \cdot w_{c} \cdot 0.909\right)
$$

where: $A=$ contact area $\left(\mathrm{m}^{2}\right) ; l_{c}=$ length of the contact $(\mathrm{m}) ; w_{c}=$ width of the contact $(\mathrm{m})$.

For other types of tyres, not experimentally measured by Febo et al. (1990), the formula 4 proposed by Komandi (1990) and the formula 5 proposed by Grecenko (1995) were used to compute the contact area (A):

$$
A=\frac{K \cdot G_{t}^{0.7} \cdot \sqrt{\frac{w_{t}}{d_{t}}}}{P_{i}^{0.45}}
$$

where: $A=$ contact area $\left(\mathrm{m}^{2}\right) ; K=$ constant depending from soil type (compacted $0.15-0.20$; rather loose $0.30-0.32$; loose sand $0.42-0.44) ; G_{t}=$ weight applied to the tyre $(\mathrm{kN}) ; w_{t}=$ tyre width $(\mathrm{m}) ; d_{t}=$ tyre diameter $(\mathrm{m}) ; P_{i}=$ inflation pressure $(\mathrm{kPa})$

$$
A=1.57 \cdot\left(d_{t}-r_{i}\right) \cdot \sqrt{d_{t} \cdot w_{t}}
$$

where: $w t=$ tyre width $(\mathrm{m}) ; r i=$ index $\operatorname{radius}(\mathrm{m}) ; d t=$ tyre diameter $(\mathrm{m})$.

Therefore the contact area (A) computed through the formulae 3, 4 and 5 were used to estimate the mean pressure $\left(M_{p}\right)$ applied on the ground by each of the 783 tractors with their fitted tyres, in order to take into account the differences occurred in the various periods examined, in the tyres (cross ply, radial ply, aspect ratio, rim, etc.). 


\section{RESULTS AND DISCUSSION}

The first result emerged is that, varying the period (years groups), the tyres change from cross-ply to radial, their denomination changes according to the new one defined by the European Tyre and Rim Technical Organisation (ETRTO), their aspect ratio (ratio, expressed as \%, between nominal height and width of tyre section) keeps decreasing from 100 to 70 and even $65 \%$, and the rim diameter keeps increasing, reaching values of 50" for the biggest tyres.

Also the average power $(\mathrm{kW})$ keeps increasing from $90 \mathrm{~kW}$ in the $1980 \mathrm{~s}$ up to $150 \mathrm{~kW}$ after 2010 . The weight/power ratio decreases from 70 to $60 \mathrm{dN} / \mathrm{kW}$, together with the reduction of $2 \mathrm{WD}$ tractors.

Figure 3 shows the averaged minimum, mean and maximum pressure (MPa) applied by the tractors onto the ground in different periods. While in the first periods examined the ground pressure is always lower than $0.15 \mathrm{MPa}$, the increasing of the values, especially after 2004 , is evident. The mean values increase from $0.07-0.08 \mathrm{MPa}$ up to $0.1 \mathrm{MPa}$, while the maximum values are even higher than $0.2 \mathrm{MPa}$ after 2010.

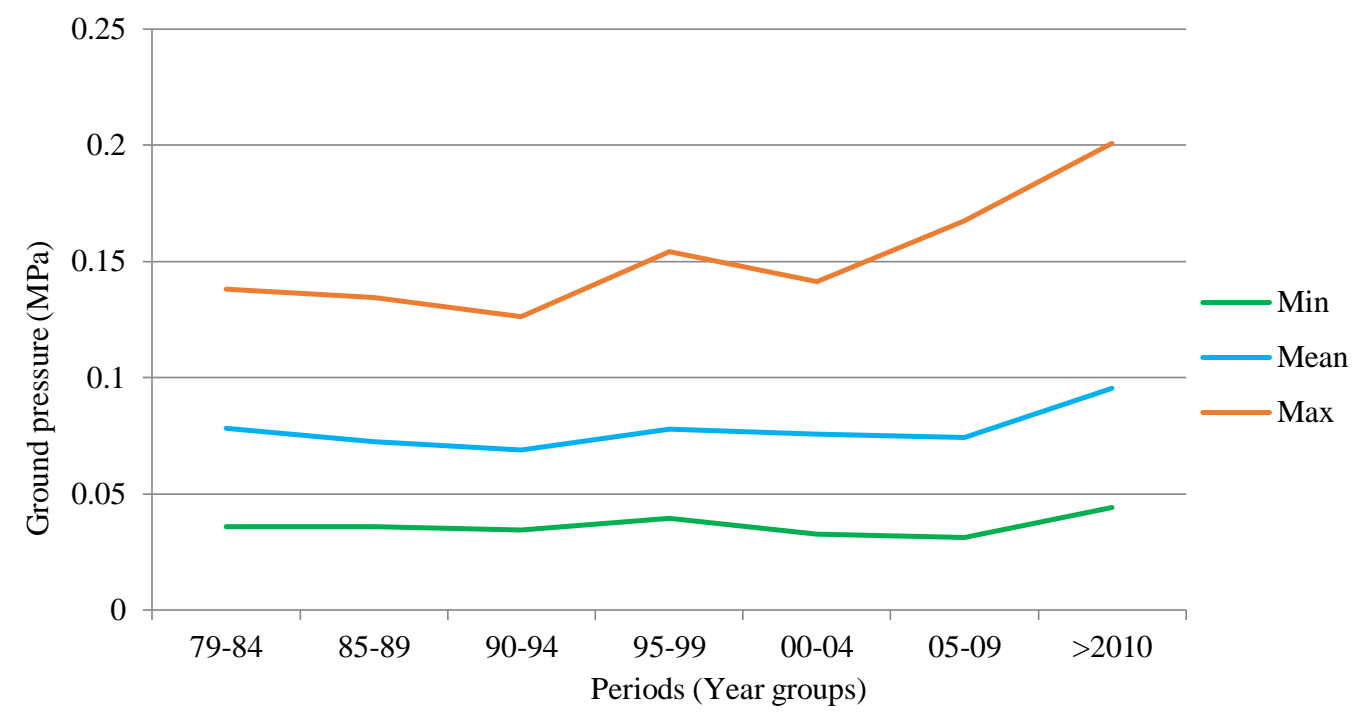

Figure 3. Minimum, mean and maximum pressure (MPa) applied by the tractors onto the ground in different periods.

Figure 4 shows the number of tractors and distribution (\%) in different periods, according to ground pressure classes (MPa). While up to 2005 the majority of the tractors exert ground pressures of 0.05-0.1 MPa, after 2010 ground pressures values are even higher than $0.15 \mathrm{MPa}$.

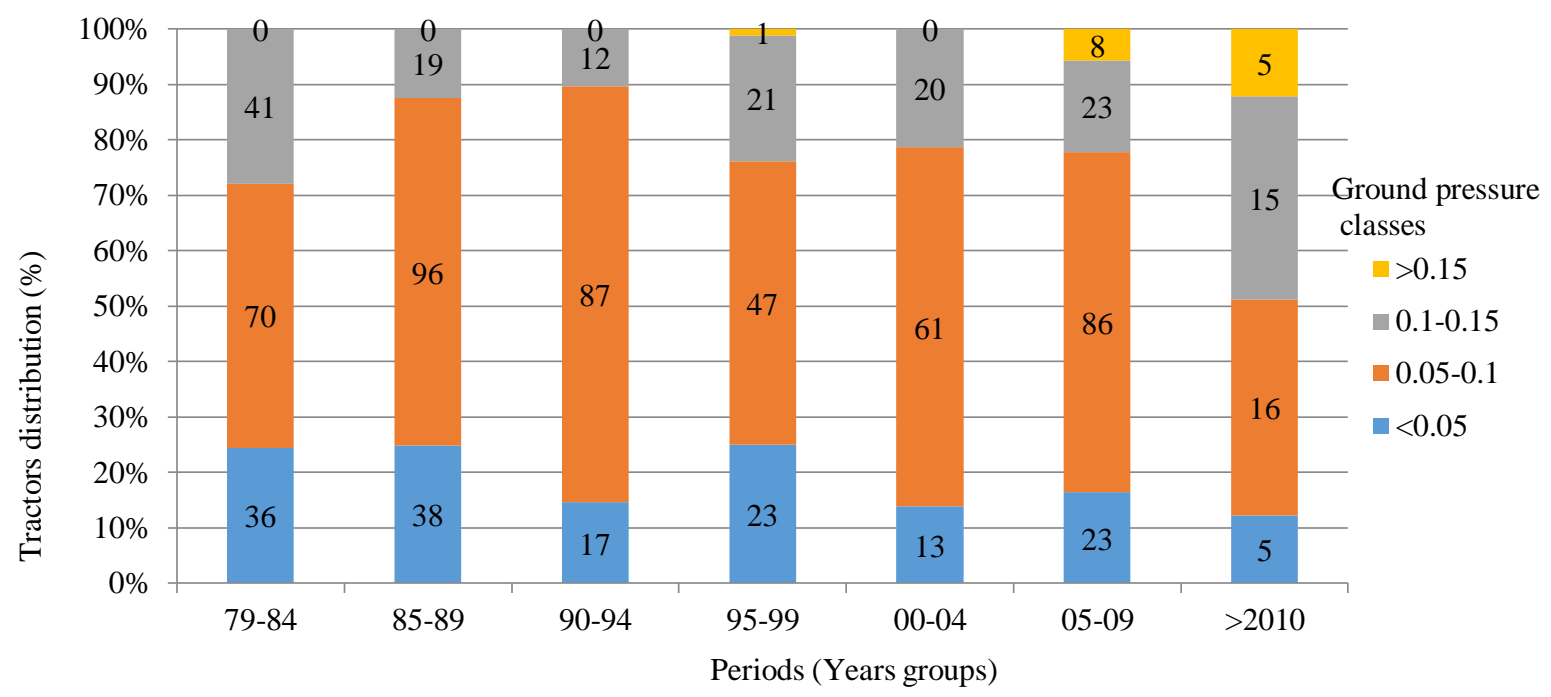

Figure 4. Number of tractors and distribution (\%) in different periods according to ground pressure classes (MPa). 
Figures 3 and 4 demonstrate that after 2005 the ground pressure increases, despite of the decrease of the weight/power ratio. Moreover, after 2010 almost $50 \%$ of the tractors exert ground pressures higher than $0.1 \mathrm{MPa}$ (and $15 \%>0.15 \mathrm{MPa}$ ). This means that tractor manufacturers have not bore in mind soil compaction.

Figure 5 shows the average ground pressure of the 783 examined tractors, related to their power and to the periods/year groups considered, distinguished by colours and symbols. It is evident that average ground pressure increases with increasing power and in the more recent periods. In particular: tractors up to $75 \mathrm{~kW}$ exert ground pressures of 0.4-0.75 MPa almost in all the periods; tractors with power of 75-130 kW exert ground pressures of 0.05-0.12 MPa; tractors with power higher than $130 \mathrm{~kW}$ exert ground pressures even of $0.2 \mathrm{MPa}$, especially after 2005 and with power of $170-220 \mathrm{~kW}$. Also these results are not in favour of soil compaction prevention.

Therefore, the above results were similar to those obtained by Pessina et al. (2002). In fact, these authors took into consideration three different power classes (low, medium and high) of tractors, equipped with the maximum ballast but not linked with any implement, so that the ground pressure resulted only $0.1 \mathrm{MPa}$ ca., with a maximum value lower than 0.13 MPa. Instead, for tractors whose three-point hitch is linked with an implement, the weight of tractor-working machine (e.g. sprayer with full tank) can easily increase by $50 \%$ and more. Therefore, they expected that the ground pressure, above all by the rear tyres, significantly increases. In several situations the tractors caused the highest ground pressure, even if the loads on the axles were relatively low. In fact, all the machines examined by Pessina et al. (2002) caused mean ground pressure much higher than the values suggested by Vermeulen and Perdok (1994) for defining a low soil compaction traffic (standard mean ground pressure lower than $0.1 \mathrm{MPa}$ ).

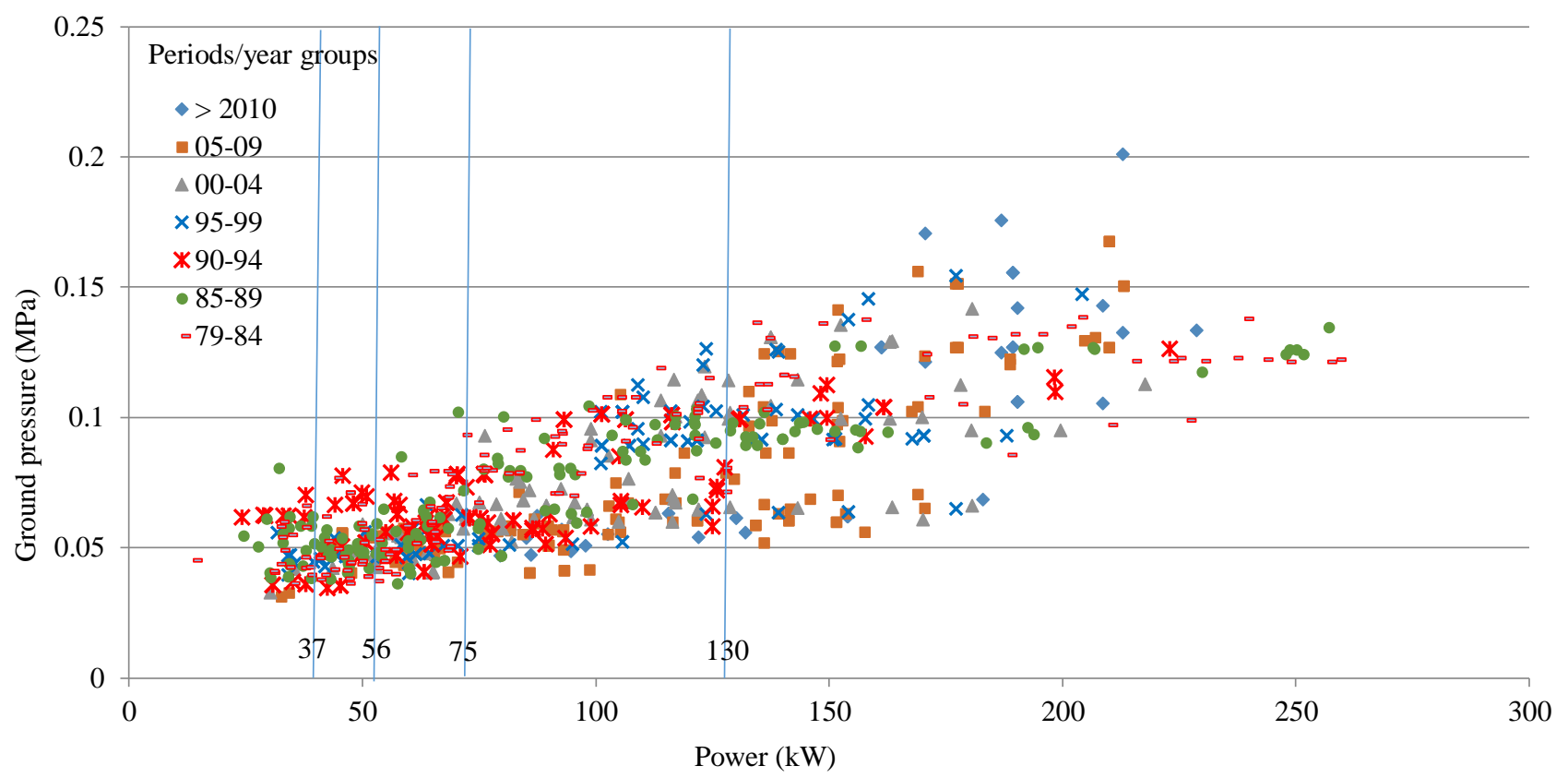

Figure 5. Ground pressure of the 783 tractors related to their power and periods/year groups (colours and symbols).

\section{CONCLUSIONS}

The analysis carried out, examining 783 OECD and Italian homologation wheeled tractor test reports, shows the changes occurred in the last 40 years in terms of maximum power, weight/power ratio, type of mounted tyres and estimated average pressure exerted on the ground.

A limit of this research could be that the tyre contact area was estimated using models (i.e. Hallomborg, Komandi, Febo) created with experimental tests carried out only using tyres existing at that time (before the year 2000) and, therefore, not using the new generation low pressure tyres, having higher flexibility, width, rims and volumes.

Nevertheless, the research shows that in the examined periods:

1) the average power is increased and the production of $2 \mathrm{WD}$ tractors is strongly decreased;

2) the weight/power ratio is diminished from 70 to $60 \mathrm{dN} / \mathrm{kW}$;

3) while in the 1970s most tractors were fitted with cross-ply tyres, nowadays almost all tractors are fitted with radial tyres with aspect ratio values lower than $85 \%$ and even of only $65 \%$;

4) the average ground pressure is increased, especially for tractors having a power higher than $100 \mathrm{~kW}$. 
In spite of the fact that recently some manufacturers of very big tractors offer the possibility of fitting their tractors with a device that allows to vary the tyre pressure directly from the driver seat, it can be concluded that tractor manufacturers have not much bore in mind the problem of soil compaction, that is one of the factors causing soil degradation.

Therefore, a higher attention is needed by manufacturers in designing machines that don't pass the above limit of 0.1 $\mathrm{MPa}$, by decreasing the loads and/or increasing the soil contact area.

\section{REFERENCES}

1. Atwell B. 1990. The effect of soil compaction on wheat during early tillering. New Phytologist, Vol. 115, Iss. 1, pp. 43-49. https://doi.org/10.1111/j.1469-8137.1990.tb00920.x

2. Benedetti A., De Bertoldi S. 2000. Qualità del suolo: criteri di definizione. In: Memorie di Scienze Fisiche e Naturali, volume 118” Rendiconti della Accademia Nazionale delle Scienze XL, vol. XXIV, pp. 189-204. http://media.accademiaxl.it/memorie/S5-VXXIVP1-2-2000/Benedetti-DeBertoldi189-204.pdf (In Italian)

3. Carrara M., Comparetti A., Febo P., Morello G., Orlando S. 2003. Mapping soil compaction measuring cone penetrometer resistance, $4^{\text {th }}$ European Conference on Precision Agriculture (4ECPA), Berlin, Germany, 15-19 June 2003, pp. 1-8.

4. Carrara M., Castrignanò A., Comparetti A., Febo P., Orlando S. 2005. Multivariate geostatistics for assessing and predicting soil compaction. Proceedings of the $5^{\text {th }}$ European Conference on Precision Agriculture (5ECPA), Uppsala, Sweden, 9-12 June 2005, pp. 723-730.

5. Carrara M., Castrignanò A., Comparetti A., Feb, P., Orlando S. 2007. Mapping of penetrometer resistance in relation to tractor traffic using multivariate geostatistics. Geoderma, Vol. 142, Iss. 3-4, pp. 294-307. https://doi.org/10.1016/j.geoderma.2007.08.020

6. Comparetti A., Febo, P., Orlando, S.,2010. Survey of the Mean Pressure Exerted by a Wide Range of Tractors on the Soil. International Conference Ragusa SHWA2010 "Work safety and risk prevention in agro-food and forest systems", Ragusa IblaCampus, Italy, 16-18 September 2010, pp. 1-5.

7. Comparetti A., Febo P., Orlando S. 2013. A system for the real-time geo-referenced measurement of soil parameters. Bulgarian Journal of Agricultural Science, Vol. 19, Iss. 6, pp. 1253-1257.

8. Dexter A.R., Horn R., Holloway R., Jakobsen B.F. 1988. Pressure transmission beneath wheels in soils on the Eyre Peninsula of South Australia. Journal of Terramechanics, Vol. 25, Iss. 2, pp. 135-147. https://doi.org/10.1016/0022-4898(88)90020-1

9. European Commission, 2005. Directive 2005/13/EC of 21 February 2005, Official Journal of the European Union of 1.3.2005, pp. 36-54. https://eur-lex.europa.eu/eli/dir/2005/13/oj

10. European Commission. 2005. Directive 2005/25/EC of 14 March 2005, Official Journal of the European Union of 8.4.2005, pp. 1-34. https://eur-lex.europa.eu/eli/dir/2005/25/oj

11. European Commission, 2006. Thematic strategy for soil protection, COM (2006) 231. Bruxelles, 22.9.2006. https://eurlex.europa.eu/legal-content/EN/TXT/?uri=CELEX:52006DC0231

12. Febo P.,1991. Il compattamento del terreno agrario: i danni e le possibili soluzioni (Soil compaction: the damages and the possible solutions). Dossier. Che cos'è e come si presenta, Macchine \& Motori Agricoli. Il Trattorista, Vol. 10, pp. 55-62. (In Italian)

13. Febo,P., Pessina D. 1987. Contact area tests of a new wide section agricultural tyre, Proceedings of the " 9 th ISTVS International Conference", Barcelona, Spain $31^{\text {st }}$ August $-4^{\text {th }}$ September 1987, pp. 236-243.

14. Febo, P., Lucarelli, F., Pessina, D., 2000. Soil-tyre interaction parameters influencing soil compaction: a study of contact area prediction models. Advances in Geoecology, Vol. 32, pp. 191-201.

15. Grečenko A. 1995. Tyre footprint area on hard ground computed from catalogue values, Journal of Terramechanics, Volume 32 , Issue 6, November 1995, Pages 325-333, https://doi.org/10.1016/0022-4898(96)00003-1

16. Hallonborg U. 1996. Super ellipse as tyre-ground contact area. Journal of Terramechanics, Vol. 33, Iss. 3, pp $125-132$. https://doi.org/10.1016/S0022-4898(96)00013-4

17. Komandi G. 1976. The determination of the deflection, contact area, dimensions, and load carrying capacity for driven pneumatic operating on concrete pavement. Journal of Terramechanics, Vol. 13, Iss. 1, pp. 15-20. https://doi.org/10.1016/0022-4898(76)90028-8.

18. Komandi G. 1990. Establishment of soil-mechanical parameters which determine traction on deforming soil. Journal of Terramechanics, Vol. 27, Iss. 2, pp 115-124. https://doi.org/10.1016/0022-4898(90)90004-6

19. Pagliai M. 2009. Qualità del suolo per una selvicoltura sostenibile (Soil quality for a sustainable selviculture). Atti del "Terzo Congresso Nazionale di Selvicoltura". Accademia Italiana di Scienze Forestali, pp. 454-459. https://doi.org/10.4129/CNS2008.064 (In Italian)

20. Pessina D., Febo P., Orlando S., Vallone M. 2002. La pressione esercitata dai mezzi agricoli sul terreno (The ground pressure exerted by agricultural machines), Rivista di Ingegneria Agraria Vol. 4, pp. 39-47. (In Italian)

21. Plackett C.W. 1984. The ground pressure of some agricultural tyres at low load and with zero sinkage. Journal of Agricultural Engineering Research, Vol. 29, pp.159-166. https://doi.org/10.1016/0021-8634(84)90070-2

22. Schwanghart H. 1994. Effect of reduced tire inflation pressure on agricultural tires, Proc. " $\sigma^{\text {th }}$ European ISTVS Conference", Wien 28 30.9.1994, Book 1, pp. 277-294.

23. Tijink F.G.J. 1994. Quantification of vehicle running gear (Chapter 17), on Developments in Agricultural Engineering, Vol. 11, Elsevier, Amsterdam, pp. 391-415, https://doi.org/10.1016/B978-0-444-88286-8.50025-8 . 
24. Vermeulen G.D., Perdok U.D.,1994. Benefits of low ground pressure tyre equipment (Chapter 17), on Developments in Agricultural Engineering, Vol. 11, Elsevier, Amsterdam, pp. 447-478, https://doi.org/10.1016/B978-0-444-88286-8.50027-1

25. Vignozzi N. 2000. Indicatori atti a quantificare alcuni aspetti della degradazione fisica del suolo (Indicators for quantifying some aspects of soil physical degradation). In: Memorie di Scienze Fisiche e Naturali, Vol. 118" - Rendiconti della Accademia Nazionale delle Scienze XL, vol. XXIV, pp. 275-284. http://media.accademiaxl.it/memorie/S5-VXXIV-P1-2-2000/Vignozzi275-284.pdf (In Italian)

26. Yong R., Boonsinsuk P., Fattah E.A. 1980. Tyre load capacity and energy loss with respect to varying soil support stiffness. Journal of Terramechanics, Vol. 17, Iss. 3, pp. 131-147. https://doi.org/10.1016/0022-4898(80)90023-3 